\title{
Biociencia y jurisprudencia
}

JESÜS AYLLON

Profesor Asociado de Filosofla del Derecho, UNED

La reciente obra de J. Habermas ("El futuro de la naturaleza humana", 2002) plantea algunas cuestiones que extienden el ámbito de los límites éticos al "haber genético de la especie humana". La capacidad de manipulación genética sobre los embriones (diagnóstico de preimplantación y manipulación genética para evitar enfermedades de transmisión hereditaria) supone una capacidad decisional sobre los descendientes que afecta a los fundamentos de la autorregulación espontánea que conlleva una carga de responsabilidad futura. La disposición orgánica, que forma el origen de la biografía del nacido, puede ser ahora producto de una decisión libre y voluntaria de los progenitores que debe ser sometida a responsabilidad exigible en el futuro. La posibilidad de excluir caracteres hereditarios indeseables ino supone una forma de determinación de la propia especie en términos de mejora biológica?¿Cómo justificar la decisión de no intervención para corregir cualquier tipo de patologías? ¿Cómo establecer un criterio universalmente válido de lo in- 
deseable? No es fácil establecer una clara frontera de determinación y siempre, la intervención, supondrá una transformación perfeccionadora de la especie humana. La humanidad se encuentra en una situación crítica de cambio orientada hacia una mayor homogeneidad humana, pero icomo no evitar condicionamientos biológicos de vida futura y cargar sobre un ser humano cualquier tipo de patologías, enfermedades, sufrimientos o dependencias vitales?. Algunas veces observamos el extraño espectáculo de esta homogeneidad en la estética dominante, resultando difícil muchas veces descubrir detrás de la cosmética las singularidades personales (modelación de cuerpos par conseguir la adecuación a los cánones dictados por los creadores de las imágenes corporales ideales). ¿Será la actuación genética un campo análogo de homogeneización orgánica?. Si los progenitores tienen la capacidad de decidir sobre el embrión que debe ser implantado ino se decidirán sobre el que tiene mejores cualidades genéticas si éstas pueden ser conocidas?.

La capacidad de determinación sobre la configuración orgánica de los descendientes nos ha situado en un difícil dilema: responsabilidad por haber hecho (actuación genética terapéutica) o por omisión (no haber actuado o actuar limitadamente). No podemos negar, desde las situaciones concretas, que ciertas actuaciones (evitar enfermedades degenerativas o limitativas de la autonomía ) pueden gozar de un universal reconocimiento pero que, desde una concepción más general, este tipo de intervenciones tiene inevitables efectos sobre la humanidad en su conjunto. Los grandes valores que configuran un horizonte de lo deseable son imposibles sin la referencia a los contravalores indeseables. Salud y enfermedad, placer y dolor, felicidad y desdicha, etc. son elementos necesarios para la una cosmovisión humana natural. Las concepciones de un "mundo mejor pero imperfecto" ha sido y es el horizonte ideal de la acción humana individual y colectiva. Era nuestro horizonte utópico. Sin embargo, el mundo feliz, desde la visionaria obra de A. Huxley, se ha situado en el horizonte no deseable de la evolución humana. El progreso científico nos está situando en una posición de de- 
terminación desconocida hasta ahora. Hoy es posible tomar decisiones sobre las condiciones genéticas de nuestros descendiente y el azar, como fundamento de las condiciones naturales del ser humano, ha visto seriamente reducido su espacio de determinación. ¿Cómo condenar a nuestros descendientes a padecer condiciones biológicas que supongan una carga para su vida futura pudiendo haberlas evitado?. Los limites de intervención parecen necesarios pero resulta difícil su determinación. ¿Dónde termina la intervención genética terapéutica?¿Debe ser la dignidad humana, entendida como determinadas condiciones de vida, el límite de toda intervención?¿Es la dignidad humana un valor de no intervención en esta primera fase de la vida? ¿Debe estar la dignidad presidida por una intervención limitada a garantizar condiciones de autonomía, entendida como capacidad para gobernarse de modo autónomo sin estar sometido a una completa dependencia para la realización de actividades vitales básicas?.

Una vez más, las soluciones jurídicas, se encuentran condicionadas por la incertidumbre o la balbuciente indeterminación del universo moral. Nuestro ordenamiento jurídico sigue manteniendo concepciones ancestrales en la definición de la "persona física", el concepto morfológico presente en nuestro Código Civil -bajo el enunciado de "figura humana"- responde a la concepción científica de las "clases y categoría basadas en criterios morfológicos" que hoy se encuentran superados.

A nuestro juicio, resulta imprescindible que las sociedades construyan un "horizonte ético" que sirva de orientación a la acción jurídica. Las normas jurídicas deben seguir el camino de lo prudencial y establecer límites a la acción científica. No es posible asumir colectivamente la libertad absoluta del quehacer científico justificado en la idea de progreso. El progreso científico debe tener siempre los límites del interés humano en su sentido colectivo, como progreso para la humanidad.

La interpretación de las normas jurídicas, dentro de la praxis judicial, no es ajena a las concepciones valorativas dominantes sobre el mundo de los hechos. En un momento y en un universo dominado por las in- 
certidumbres, no puede resultar extraño que la interpretación jurídica de los tribunales esté orientada por un cierto neutralismo moral que hace descansar en la exégesis normativa la responsabilidad personal.

En éste, como en otros muchos ámbitos del Derecho, el valor de la "dignidad humana" constituye uno de esos conceptos de contenido indeterminado que, sin embargo, goza de reconocimiento universal. Las diferentes concepciones éticas suministran soluciones claramente diferenciadas y, en sociedades en las que "las cosmovisiones sobre el universo de los valores y su jerarquización" son plurales, no es extraño que se proyecte sobre la regulación legislativa y sus interpretaciones, las "precomprensiones" de los diferentes operadores jurídicos y que se acepte una posición de consenso basada en criterios de "interpretación exegética" que resulta problemática si, como en otros muchos casos, el consenso regulativo se construye más sobre la propia indeterminación del contenido que sobre una significación aceptada universalmente aunque sea de contenido mínimo. En este terreno, debemos confesar que estamos profundamente condicionados por la lectura de los debates y posiciones sostenidas por los representantes nacionales en las Naciones Unidas cuando se pactó la Declaración Universal de Derechos Humanos de 1948.

Es innegable que existió un consenso terminológico - los enunciados gozaron de aprobación universal- pero también es cierto que la delimitación de contenido de los diferentes derechos no fue tan universal (1). El propio "derecho a la vida", cuyo contenido puede parecernos, parece, inequívoco, sin embargo, tropieza con interpretaciones extensas y mínimas fundadas en argumentos que se entienden razonables (aceptación/rechazo de la pena de muerte, aborto, eutanasia, etc). El resultado es que, en los diferentes universos culturales, el campo de las excepciones se multiplica de tal modo que no se si se pueda hablar de un contenido mínimo universalizable. La pretensión de Adela Cortina de una ética mínima me parece un loable intento en esta pretensión de universalización de principios morales. Es posible que la universalización de 
los derechos humanos tenga que pasar por el consenso de contenidos mínimos.(2)

En el espacio de la biociencia, parece abrirse camino, progresivamente, la idea de la necesaria subordinación a la ética y la negación de un pretendido neutralismo ético conforme al cual, regiría el principio de validez de "hacer todo lo que sea posible, realizar todos los experimentos y promover todas las investigaciones sin más limites que los derivados de la capacidad humana", aunque su sistema de justificación descansa en la idea de "progreso" y las consideraciones sobre su bondad o maldad se traslada al buen o mal uso del conocimiento o del artefacto. El principal problema es la identificación de progreso técnico y progreso humano y la autonomía de la "razón técnica" y "razón científica" frente a la "razón humana"( nos permitimos recordar a este respecto la crítica de la Escuela de Frankfurt sobre el neutralismo de la ciencia) (3).

En el debate ético nos encontramos, aún a sabiendas del reduccionismo en el que incurrimos, dos grandes tradiciones culturales. Una, enraizada en el mundo sajón, conocida como utilitarista, que es la dominante en los universos científicos de los países más desarrollados, que parte de una exigencia legitimadora de carácter finalista: el juicio valorativo con arreglo a los fines. Su enunciado moderno es el fin de la "calidad de vida" que ha permitido justificar, en ciertas posturas, la muerte en aquellas vidas sin calidad. La dignidad humana quedaría subsumida en esa "calidad de vida" que se propone como paradigma de la decisión autónoma e incluso heterónoma (suicidio, eugenesia o eutanasia). Es preferible la muerte a una vida puramente vegetativa o absolutamente dependiente. Idea que puede conducir a la "lebensunwerte Leben" (vidas sin valor de vida), utilizado por la ideología hitleriana y que sirvió de justificación al genocidio y el experimentalismo científico con seres humanos. En la cosmovisión bioética sajona, los tres principios éticos que se sitúan como límite serían: el principio de beneficencia, el de autonomía y el de justicia. El carácter individualista que preside su concepción ha permitido fortificar la autonomía decisional del 
individuo frente a cualquier acción externa con independencia de su justificación. La consecuencia más valiosa, a nuestro juicio, en el campo terapéutico, ha sido la exigencia del "consentimiento informado" que hoy constituye un principio bastante universal e incorporado a los catálogos de derechos de los enfermos.

La otra, entendida como concepción objetivista, enraizada en la tradición kantiana, parte de un presupuesto contrario. El hombre posee una dignidad que le es consustancial y, en consecuencia, constituye un bien que debe ser protegido. Esta dignidad exige, entre otras cosas, la negación de su valor instrumental: el hombre como medio. En esta perspectiva los desarrollos biomédicos no pueden negar la dignidad humana (no utilización del hombre como instrumento para otros fines) (4). El respeto de la vida humana - de la dignidad humana- sería el primer imperativo ético desde esta concepción. ¿Cómo armonizar ambas concepciones?

Si la dignidad es entendida como "calidad de vida", y una vida digna exige una vida "cualitativa" porque si no, no vale la pena su conservación, el problema se traslada al significado de la "calidad de vida". Ciertos movimientos a favor de la eutanasia -incluso activa- parten de una concepción de la "calidad de vida" que sirve de justificación a las prácticas correspondientes. La única limitación ética que se aceptaría es la de la "autonomía" (testamento vital). La ética biomédica sajona ha erigido este "principio de autonomía" en principio ético supremo de la relación médico-paciente, sin ninguna vinculación con un bien que trascienda a los sujetos. Esta fundamentación sería extrapolable al campo de la decisión sobre la intervención correctora -terapeútica- en los embriones que deban ser objeto de implantación, con la notable diferencia de que esta decisión no es autónoma del sujeto sino de aquellos a quienes se confiere la capacidad de procrear.(5)

¿Qué concepción ética debe presidir la acción legislativa?¿Debe ser el campo legislativo un espacio neutro?¿Debe incorporar ese mínimo ético que proponen algunos autores? 
Analizando nuestro ordenamiento jurídico, nos encontramos que nuestro marco constitucional, no está exento de algunos de estos problemas de indeterminación. En algún artículo publicado señalábamos que, la indeterminación de ciertos artículos de nuestra Constitución de 1978, había convertido al Tribunal Constitucional en auténtico legislador modificando el sistema general de fuentes del derecho enunciado en nuestro Código Civil. Algunos constitucionalistas como Álvarez Conde, han planteado esta misma cuestión y reconocen el valor de fuente de nuestra jurisprudencia constitucional. (6)

El valor de la "dignidad humana" se recoge en el art. 10.1 CE., lo que supone, aceptando las conclusiones del análisis sistemático del texto efectuado por autores como Pérez Luño, su exclusión como "derecho fundamental" constitucionalizado y, en consecuencia, excluido del sistema de garantías establecido para los derechos fundamentales.(7)

Así, no puede sorprender dentro de la lógica argumental, que el TC se haya manifestado en este mismo sentido, señalando que no puede servir de fundamento para el recurso de amparo (SSTC. 27/82, 64/86, 101/87, 265/93, 136/96 y 204/97). Para el Tribunal Constitucional, la dignidad es fundamento de los demás derechos subjetivos y uno de principios axiológicos fundamentales de la $\mathrm{CE}$ : "Indisolublemente relacionado con el derecho a la vida....se encuentra el valor juridico fundamental de la dignidad de la persona, reconocido en el art.10 como germen o núcleo de unos derechos que le son inherentes" (STC 53/85, de 11 de abril). Coincidimos en la valoración de Pedro Serna (1999), cuando afirma que "el principio de dignidad (es utilizada) proyectándola sobre uno o varios derechos fundamentales, nunca como "ratio decidendi" autónoma e independiente". (8)

A diferencia del citado autor, consideramos que la visión positivista que opera en nuestro ordenamiento jurídico (la visión kelseniana del sistema jurídico sigue fundamentando el campo doctrinal de la mayor parte de las teorías fundamentadoras de las distintas ramas del derecho con inclusión del propio derecho constitucional. Recordemos el mero hecho 
de la modificación nominal de la materia en los planes de la Licenciatura de Derecho pasando de "Derecho político a Derecho Constitucional. Detrás de esta denominación ino existe un cambio conceptual?).(9)

Critica, el citado autor, que el concepto de dignidad utilizado por el TC es ambiguo y contradictorio y que rechaza expresamente adoptar una concepción determinada para no consagrar ninguna construcción dogmática particular, aunque reconoce, más adelante, una aproximación a lo que podría ser una definición y cita "la dignidad es un valor espiritual y moral inherente a la persona que se manifiesta singularmente en la autodeterminación consciente y responsable de la propia vida y que lleva consigo la pretensión al respeto por parte de los demás".

El análisis critico de la jurisprudencia constitucional de P. Serna, de innegable valor, en su dimensión lógico argumentativa, es más discutible en su pretensión dogmático-conceptual. Esquematizando su argumento, "para aplicar el principio jurídico-moral de la "dignidad humana" es imprescindible una definición dogmática que permita establecer su contenido concreto, como no lo hace, debido al "prejuicio de inspiración formalista-positivista", incurre frecuentemente en contradicciones. Pero, ino es la dogmática un fundamento de la posición formalistapositivista que el propio autor critica?. Bien es verdad que desde nuestro conocimiento de la obra de este autor, debemos matizar la proposición puesto que su posición es más "dogmático substancialista" que "dogmático formalista"

Desde nuestra perspectiva sociológica, siempre entendimos que uno de los problemas de la "dogmática jurídica" era la transformación forzada del caso concreto al tipo. La categorización forzada de lo real es siempre una forma de reduccionismo. Toda clasificación tipológica es necesariamente insuficiente y reduccionista. No negamos el valor de la dogmática como elemento orientador y limitativo de la discrecionalidad, a pesar de que consideramos inevitable e ilusa cualquier pretensión de reconducir la diversidad compleja a tipos y eliminar una cierta discrecionalidad interpretativa en el proceso de formalización. A pesar de las 
construcciones dogmáticas, las soluciones discrepantes inundan nuestra jurisprudencia y nos obliga a introducir un criterio de autoridad para corregir las discrepancias. El recurso de casación para la "unificación de la doctrina" introducido en el sistema procesal es un recurso dogmático no referido a la solución racional del principio de veracidad incontrovertido, sino a la verdad establecida por el órgano al que se reconoce la capacidad decisional. Se puede criticar porque las cosmovisiones operantes en nuestro campo cultural no atribuyen el "dogma de la infalibilidad" a persona u órgano alguno. Este principio de veracidad no se contempla prácticamente en ningún universo cognitivo occidental salvo en el campo de las creencias religiosas del mundo católico con respecto al Summo Pontífice y esto referido solo a determinadas materias.

El problema de los principios éticos y del consenso estuvo presente en los trabajos de la Comisión Nacional, creada por el Congreso de los EEUU., para establecer unos principios éticos básicos que orientaran la investigación con seres humanos. El consenso se obtenía en el nivel de los juicios particulares (casos concretos), sin embargo cuando se remontaban al nivel de los principios (razones de la coincidencia en la valoración ética del caso concreto, el acuerdo era imposible. (10). ¿Debe el Derecho configurar unos mínimos éticos?. ¿Debe el Derecho permanecer neutral frente al pluralismo moral?. Martín Mateo, argumenta que "las constituciones no son buenas ni malas éticamente: a lo más pueden ser acertadas o erróneas en cuanto al discernimiento por los constituyentes de las convicciones comunitarias"(11).

Manuel Atienza formula una propuesta diferente en lo que denomina "juridificar la ética" y que consistiría en establecer una "conexión metodológica" que si hemos entendido bien, consiste en aplicar la "racionalidad jurídica" a los conflictos que envuelven principios en sentido estricto y que plantean exigencias incompatibles entre sí.. Este autor señala como principios universales los de la ética kantiana de autonomía, dignidad, universalidad y publicidad que, aplicados a la bioética se traducen en los siguientes: 
- Cada individuo tiene derecho a decidir sobre aquello que le afecta (vida y salud).

- Ningún ser humano puede ser tratado como un simple medio (dignidad).

- Quienes estén en las mismas condiciones deben ser tratados de igual manera.

- Todos los individuos tienen derecho a saber lo que les afecta.

Estos principios serían aplicables a los casos fáciles, pero como resultan insuficientes para resolver los casos difíciles, propone una serie de nuevos principios: paternalismo justificado - utilitarismo restringido- trato diferenciado - secreto. Pero, como además esta serie de principios (suponiendo que se acepten) no permiten resolver, sin más ayuda, la diversidad de casos difíciles que pueden surgir en la bioética, es necesario concretar una serie de reglas. Construido el esquema analítico, plantea la conveniencia de Comités de bioética que actúen al modo jurídico produciendo una "especie de jurisprudencia"(12). No deseamos entrar en un análisis crítico del esquema analítico y sus fundamentos, pero si debo manifestar que aún aceptando las reglas, su aplicación a un desbordante universo de casos singulares y que nos veríamos obligados a una ampliación de las categorías analíticas. Mucho nos tememos que las insuficiencias de los principios y reglas, en el campo jurídico, serían extensivas al campo de esa "jurisprudencia ética". No estamos convencidos de que los Comités Científicos actuando al "jurídico modo" puedan sustituir a los órganos jurídicos y creemos preferible el control externo que el interno. Aunque, en muchos campos científicos, es impensable la posibilidad de articular un control externo que no cuente con la colaboración técnica de científicos especializados en el correspondiente campo sometido a la decisión jurídica.

El TC se manifiesta claramente en el sentido que hemos señalado cuando dice: "las normas constitucionales relativas a la dignidad de la persona y al libre desarrollo de la personalidad.... si bien integran mandatos jurídicos objetivos... no pretenden la consagración constitucional de ninguna construcción dogmática" (STC 150/91).

Dicho lo anterior, cabe preguntarse si no existe un contenido mínimo universalizable (entendido en su sentido de consenso empírico-ra- 
cional habermasiano) o al menos, podemos preguntarnos si existe esta posibilidad en nuestro propio marco socio-jurídico.

Una respuesta afirmativa la podemos encontrar en Marcelo Palacios, Presidente del Comité científico de la Sociedad Internacional de Bioética cuando señala que "no tardando mucho los avances bio-científicos serán tantos y tan vertiginosos que los estamentos legitimados para ello, de lento metabolismo interno, no podrán seguirlos ni adoptar a tiempo la legislación estrictamente precisa, por lo que la humanidad se proveerá más de pactos civiles, acuerdos o consensos éticos universales que de leyes" y, referido a la dignidad, propone como definición: "una excelencia, realce o merecimiento" y matiza a continuación "Sin entrar en su inherencia o esencialidad que más bien contradigo, en base a su desvinculación de lo genético y hereditario-, la dignidad humana es un valor cultural diferencial que nos hemos atribuido en la etapa más reciente de nuestra evolución" (13). Si nos centramos en el ámbito europeo y, en concreto, las decisiones del Grupo de Consejeros para la ética de la ciencia y de las nuevas tecnologías, podemos observar que nos encontramos lejos del "consenso universal" que sería deseable. Acotando el campo a los problemas de "terapia génica", el acuerdo se reduce al "rechazo de tales experiencias sobre el ser humano debido a la falta de conocimientos científico-técnicos actuales", y en el de las investigaciones sobre embriones nos encontramos un Acta en la que se deja constancia de "la diversidad ética y jurídica europea en la definición del status del embrión... proponiendo como única alternativa la de la tolerancia" (1998). En el fondo subyace un profundo disentimiento filosófico sobre los conceptos de naturaleza-evolución-humanidad que no es ajeno al problema de la falta de entendimiento existente entre las distintas concepciones éticas y iusfilosóficas. El consenso obtenido sobre "principios éticos fundamentales" es bastante limitado, concretándose en la formulación "Si a la libertad de investigación, excepto si....” y establece el condicionamiento limitativo de un control externo en los siguientes planos: "los procedimiento de investigación- la finalidad declarada de los proyectos y las posibles consecuencias de los resultados". 
Sobre este contenido mínimo podemos citar el siguiente argumento utilizado por el TC : "la regla del art. $10 \mathrm{CE}$, proyectada sobre los derechos individuales, implica que la dignidad ha de permanecer inalterada cualquiera que sea la situación en la que la persona se encuentre, constituyendo un minimun invulnerable que todo estatuto jurídico debe asegurar, de modo que las limitaciones.... no conlleven un menosprecio para la estima que, en cuanto ser humano, merece la persona" (STC 57/94). A nuestro juicio, el contenido mínimo que plantea, esta presente en otras argumentaciones sobre los derechos fundamentales, recordemos al respecto la sentencia sobre la objeción de conciencia al servicio militar previo a su desarrollo normativo a través de la Ley de objeción de conciencia. En esta sentencia plantea también la cuestión del contenido mínimo del derecho. Si el objetor que no puede ser reconocido como tal en ausencia de la norma de desarrollo es obligado a cumplir el servicio militar, el reconocimiento constitucional estaría vacío de contenido.

\section{2.- EL MARCO JURÍDICO ESPAÑOL}

La legislación española específica, en el campo biotecnológico, abarca los siguientes campos:

- Extracción y trasplantes de órganos. (Ley 30/79)

- Fomento y coordinación de la investigación científica y técnica.

- Técnicas de reproducción asistida. (Ley 35/88)

- Donación y utilización de embriones y fetos humanos o de sus células, tejidos u órganos. ( Ley 42/88)

- Régimen jurídico de la utilización confinada, liberación y comercialización de organismos modificados genéticamente a fin de prevenir los posibles riesgos para la salud y medio ambiente. (Ley 15/94).

- Interrupción del embarazo (Ley Orgánica 53/1985, de reforma del Código Penal,)

- Esterilización de incapaces con graves deficiencias psíquicas (LO. 3/1989, de modificación del Código Penal) 
Si este es el campo más específico de la bioética que aparece regulado en nuestro ordenamiento jurídico, parece de especial interés circunscribir la exposición a los problemas con él relacionados, sin que entendamos que la dignidad humana puede quedar reducida a este único universo. El principal problema con el que nos hemos encontrado es el de la inexistencia de decisiones judiciales en muchos de los campos abiertos por las investigaciones biotecnológicas. Los conflictos abordados por el alto tribunal están limitados a los siguientes campos:

\section{INTERRUPCIÓN DEL EMBARAZO}

La STC 53/85, respuesta a una demanda de inconstitucionalidad, sitúa la dignidad en el plano de la visión jurídico positiva de la persona presente en nuestro Código Civil (art. 29), según el cual, el "nasciturus" no tiene personalidad y no puede ser sujeto de derechos. El nacimiento es el factor determinante de la personalidad y la colisión de derechos madre/nasciturus se resuelve a favor de la madre. La fundamentación es claramente criticada desde ciertas posiciones doctrinales que sostienen que la vida humana es un continuum desde el momento de la fecundación y, en consecuencia, el propio embrión sería sujeto de derechos. Pero ¿qué ocurre en la fase prembrionaria?¿ipueden seleccionarse genéticamente, sin limitación alguna, los óvulos y espermatozoides destinados a la fecundación?. La dignidad humana como límite debe proyectarse sobre este tipo de decisión, pero icuál es el fundamento y contenido de la dignidad en este campo clínico?

En el caso de interrupción del embarazo consecuencia de una violación, la dignidad humana, como principio jurídico fundamental, aparece referido a la dignidad de la madre frente al derecho a la vida del nasciturus. Dice el Tribunal que obligar a la madre a "soportar las consecuencias de un acto de tal naturaleza es manifiestamente inexigible; la dignidad de la mujer excluye que pueda considerársela como mero instrumento y el consentimiento necesario para asumir cualquier compromiso cobra especial relieve... ante un hecho de tanta trascendencia 
como el de dar vida a un nuevo ser, vida que afectará profundamente a la suya en todos los sentidos". Los problemas éticos que se plantean desde las posiciones señaladas pueden resumirse en las siguientes preguntas: ¿por qué establecer un límite de 12 semanas? ¿por qué la vida del nasciturus no merece protección frente a la dignidad materna?. La decisión en esta colisión de derechos se fundamenta en una valoración diferencial de naturaleza ontológica: la vida materna -persona humana plena- que exige para su desarrollo humano la protección de su dignidad y la vida del "nasciturus" - carente de esa plenitud de vida- a la que no se reconocen derechos de la personalidad. La propia Declaración Universal de Derechos Humanos (1948), reconoce el derecho a la "dignidad humana" vinculado al nacimiento: "todos los seres humanos nacen libres e iguales en dignidad y derechos". La vida física es soporte y condición necesaria de la vida humana pero no agota todas las dimensiones de lo humano. La dimensión espiritual se ubica como valor superior en la jerarquía de valores humanos. Así, la propia vida física puede ser entregada -sacrificio voluntario- a la realización de ciertos valores espirituales (acción heroica) y, en ciertas circunstancias, puede ser exigido socialmente el sacrificio de la propia vida (acción de guerra), aunque pueda ser más discutible en algún tipo de acciones militares (guerra preventiva).

Esta concepción del "nasciturus" experimenta una cierta modulación cuando se plantea cuestiones relativas a la manipulación genética. Encontramos, en este caso, que las prácticas eugenésicas negativas -terapeúticas- son admitidas como condición de una vida digna futura (eliminación de ciertas taras de transmisión genética) y completamente rechazadas las prácticas de eugenesia positiva -mejoramiento de las condiciones genéticas-. Los límites a la manipulación genética se fundamentan en la defensa de la propia identidad humana, que puede estar en peligro si se aceptan estas prácticas de manipulación genética. ¿̇e abre así el campo de experimentación con embriones para fines terapéuticos? Si la vida del "nasciturus" cede ante la dignidad de la madre, 
¿qué obstáculos poner a la utilización de embriones - que no van a tener viabilidad- para fines terapéuticos? ¿qué razones oponer a este sacrificio embrionario si se derivan efectos favorables -terapeúticos- para un número considerable de enfermos (recordemos la reacción social de apoyo a los programas de investigación del Dr. Soria, con células-madre embrionarias, por un considerable número de diabéticos de todo el mundo que ven en este proyecto la esperanza de una vida sin dependencia de la insulina). ¿Cómo no preferir el sacrificio altruista que el mero sacrificio de los embriones sobrantes?.

Salvo que se acepte el axioma de la identidad entre cualidad biológica humana y persona (existe persona desde el momento de la fecundación), que permitiría atribuir al embrión -desde el primer momento- la condición de persona depositaria de la dignidad humana; o la teoría antagónica del nacimiento de la persona desde el momento en que nace la autoconciencia (interacción social y cultura), que supondría la negación de la cualidad de persona a los embriones humanos o a los fetos y, en consecuencia, el no reconocimiento del valor dignidad -inherente solo a la persona- (13); parece abrirse camino la teoría de la evolución embrionaria durante la gestación, de modo que solo a partir de un determinado momento se puede hablar de conformación del embrión como ser humano (fundamento de las leyes de plazos para la interrupción del embarazo). Es esta la difícil barrera del salto cualitativo en el proceso de hominización que constituye una de las claves del análisis histórico de nuestro primer antepasado (el primer eslabón de la cadena del género humano, el nacimiento del "homo sapiens"). En este proceso los fundamentos se convierten en pura convención y, en consecuencia, siempre susceptible de controversia científica y ética. Creemos que es necesario el reconocimiento de un estatus singular al embrión que evite su transformación en simple materia biológica susceptible de cualquier tipo de usos comerciales o experimentales sin límite alguno, lo que no debe constituir una completa fortificación de sus derechos frente a otros derechos de análoga naturaleza. En la STC 116/1999, se señala a este res- 
pecto que "los no nacidos no pueden considerarse en nuestro ordenamiento como titulares del derecho fundamental a la vida...., lo que, sin embargo, no significa que resulten privados de toda protección constitucional". La vida de la madre tiene un estatuto moral de igual o superior nivel que la vida del nasciturus (la renuncia a la vida por parte de la madre para salvar la vida del feto en gestación avanzada, no puede dejar de ser valorada como acción moral digna de reconocimiento aunque no pueda ser exigible desde cualquier otra instancia social). Sin embargo, más discutible puede resultar la aceptación del aborto por causas económicas, cuando este tipo de causas es siempre subsanable a través de medidas de solidaridad colectiva o de políticas sociales; o la libertad discrecional de la madre sin alegación de causa alguna.

\section{LA ESTERILIZACIÓN DE INCAPACES.}

Los principios éticos de autonomía y proporcionalidad, que se expresa en el libre consentimiento y el menor daño posible para la obtención de un bien superior, son sometidos a consideración en uno de los problemas ("casos difíciles" de Dworkin), planteado por la regulación jurídica; es el de las "esterilizaciones" de incapaces psíquicos. El razonamiento del Tribunal Constitucional contempla tres dimensiones:

La defensa de la dignidad del menor, cuyo contenido se hace descansar en la libertad "no estar sometido a vigilancia constante".

El ejercicio de la sexualidad sin el riesgo de una posible procreación cuyas consecuencias no puede prever ni asumir conscientemente ni disfrutar de las satisfacciones y derechos de la maternidad y paternidad ni cumplir por si mismos los deberes inherentes.

Evitar las consecuencias que, incompresibles para ella, pueden dañar más aún su estado psíquico por las consecuencias físicas que produce el embarazo.

La dignidad del incapaz aparece vinculada a la libertad y constituiría vulneración si "La esterilización ... le permite no estar sometida a una vigilancia constante que podría ser contraria a su dignidad y a su integri- 
dad moral, haciendo posible el ejercicio de su sexualidad, si es que intrínsecamente lo permite su padecimiento psíquico", o cuando establece la ponderación con otros medios anticonceptivos "no ofrecerían la misma seguridad y certeza que la esterilización (...) ademas su adopción requeriría un control constante y continuado por parte de los guardadores, no siempre posible y por tanto aleatorio a no ser que la intervención de aquellos en la vida del incapaz sea tan intensa y rigorista.."que afectarían a su libre desarrollo y a su dignidad.

En el Auto 261/1998, que resuelve una cuestión de inconstitucionalidad, en relación con la Ley Orgánica 10/1995, con motivo de autorización de esterilización de incapaz (Tenerife); frente a las consideraciones del órgano juzgador, que plantea la "desproporcionalidad entre el fin perseguido y la solución impuesta" por el legislador y el carácter indeterminado del concepto "grave deficiencia psíquica"; considera el Tribunal que "en atención al mayor interés de la incapacitada, se impone la esterilización como medida más aconsejable para que quién no pueda conducirse por sí misma no padezca los efectos de un embarazo que podría afectar seriamente a su estabilidad emocional y personal y, al tiempo, no se vea sometida como contrapartida a prácticas anticonceptivas no menos perturbadoras para su estabilidad". Argumentación que respeta el principio del medio menos lesivo para evitar un mal mayor para la incapaz (aborto). El problema que suscita es el de la consideración del uso de otros medios anticonceptivos de carácter más reversible aunque menos seguros al fin de evitar el embarazo. Es cierto que la píldora anticonceptiva exige de un mayor control de su dispensación por parte de padres o tutores y que, en determinados casos, produce efectos secundarios que la hacen desaconsejable, pero no tanto en lo que respecta a la seguridad anticonceptiva. El método del DIU tiene ciertos niveles de inseguridad que no debe ser desdeñada a los efectos de un embarazo que no puede ser deseado como efecto por quienes tienen el deber de protección del incapaz. Es cierto que todas las alternativas "ofrecen menos seguridad y certeza" que la esterilización y que, en la actualidad, es- 
tas prácticas de esterilización masculina o femenina se han convertido en una práctica habitual como método de control de la natalidad demandado por un elevado número de ciudadanos de modo voluntario y consciente. Para estos ciudadanos, los sistemas de esterilización -vasectomía o ligadura de trompas- han perdido la fuerte carga emocional que encierra el término "esterilización", razón por la que no les cuesta asumir este tipo de intervención quirúrgica en el caso de las incapacitadas (situación que no se plantea responsablemente por padres o tutores de los incapacitados varones tal vez porque como señala el TC: "Los fines que justifican la medida de esterilización para ambos sexos... en la mujer se acrecientan o se hacen más convenientes por las consecuencias biológicas del embarazo",Auto 261/1988). La diferencia más notable entre capaces e incapaces, a efectos de esterilización, estriba en que, aparte del libre consentimiento, mientras en el primer caso se plantea, de modo mayoritario, después de haber obtenido la paternidad/maternidad con un número determinado de hijos; en el segundo, antecede a la propia maternidad y la hace imposible (la irreversibilidad -para el hipotético supuesto del milagro de la investigación neurológica que pueda resolver las deficiencias psíquicas- puede no ser tal y ser solucionada en algunos casos y tal vez -en un futuro más o menos inmediato- el progreso médico haga posible remover fácilmente el obstáculo y modificar la cualificación de estas prácticas anticonceptivas como prácticas de "esterilización" o conseguir otros métodos menos agresivos e igualmente seguros.

Los recurrentes y el propio juzgador sostienen en sus críticas la alternativa de la vigilancia sexual -negando su condición de derecho y partiendo de una concepción de la misma de carácter psíquico inalcanzable para estos incapaces-, premisa que no parece sostenible si tenemos en cuenta que la sexualidad es un instinto natural menos controlable para quien se encuentra en esa situación de "grave deficiencia psíquica" y que la integración de los minusválidos en centros educativos y laborales especiales favorece la posibilidad del contacto sexual no consciente. 
La carga emocional del término "esterilización", asociada a las políticas estatales de sistemas políticos dictatoriales, sigue operando en la percepción negativa de las actuales prácticas. El Tribunal Constitucional es reiterativo en el establecimiento de la distinción entre el sistema regulado -petición de parte legitimada, dictámenes médicos sobre la deficiencia psíquica, intervención del $\mathrm{M}^{\circ}$ Fiscal y el examen directo del interesado por el propio juez que debe tomar la decisión- y una práctica política universal que asocia con el sistema establecido en Alemania durante el régimen nazi. Así, expresamente lo manifiesta, en Auto 13/1989, cuando dice que "la norma, por la importancia del supuesto que contempla, no es susceptible de una interpretación extensiva que permita convertir en una apertura general..." y "la disposición examinada, referida siempre a un supuesto concreto y excepcional, excluye radicalmente cualquier política gubernamental sobre la esterilización de los deficientes psíquicos".

Respecto del "principio de autonomía" parece de difícil aplicación por la propia incapacidad que viciaría el procedimiento. Los sectores contrarios a estas prácticas formulan diferentes reparos: ¿Debe ser el consentimiento de los padres suficiente para la decisión de esterilización?¿No se está protegiendo el propio interés de los padres y familiares frente a los del menor como plantean, en votos particulares, dos magistrados ?. Consideramos que mientras existe una opinión generalizada de condena moral sobre la universalización de estas prácticas y de modo singular sobre la adopción de políticas gubernamentales de esterilización que afecte a determinados grupos humanos, el sistema adoptado por el legislador español y especialmente, su sistema de garantías, no permite avalar una condena radical. La exigencia de su singularización ( autorización expresa que debe tener en cuenta las circunstancias de cada caso) y, mientras no se desarrollen procedimientos anticonceptivos menos lesivos, puede defenderse y su justificación moral, desde una perspectiva teleológica, como la sostenida por el Tribunal Constitucional pueda ser sostenida como mal menor inevitable frente a alternativas 
como la del aborto que nos parecen especialmente traumáticas para estos incapaces.

\section{3.- UTILIZACIÓN DE EMBRIONES.}

Una de las cuestiones más controvertidas en el campo de la fecundación artificial es el uso de técnicas de diagnóstico preimplantatorio y la selección de donantes. Si bien, su uso como forma de "eugenesia negativa" (descartar deficiencias genéticas), encuentra no pocos argumentos éticos de defensa; la técnica puede permitir una apertura a modalidades de "eugenesia positiva" (selección de sexo, raza, etc) que permitan cumplir los deseos de los padres o sistemas de control demográfico (limitación de nacimientos femeninos).(14)

Las críticas a toda modalidad de "eugenesia positiva" suelen fundarse en la defensa de la "biodiversidad", pero este fundamento puede ser proyectado también sobre la necesidad de mantener seres humanos incapaces, disminuidos físicos o psíquicos, etc.; la humanidad, sin esta presencia, será bastante diferente, será menos humana, si lo humano está caracterizado por la imperfección, y desaparecerán los elementos de referencia necesarios para sentirnos más humanos.

En nuestro universo jurídico, la concepción jurisprudencial está presente en la decisión judicial que se produce como consecuencia de un recurso de inconstitucionalidad sobre la Ley 42/1988, que regula la donación de órganos y utilización de embriones y fetos humanos o de sus células.

Los recurrentes defienden sus pretensiones en el "principio de dignidad de las personas" que estiman incompatible con la patrimonialización de la vida humana al aceptarse la donación y la equiparación entre los fetos o embriones muertos y los clínicamente no viables.

El Tribunal desestima la pretensión que basa en los siguientes argumentos: 
La equiparación entre muertos y no viables esta justificada en la "no viabilidad -incapacidad para desarrollarse hasta dar lugar a un ser humano- . Son embriones o fetos humanos abortados en el sentido más profundo de la expresión, es decir frustrados y susceptibles de utilización con fines diagnósticos, terapéuticos, de investigación o experimentación".

Se establece una clara distinción entre preembriones no implantados e implantados en el útero materno y los gametos (ovocitos y espermatozoides antes de la fecundación). Señalando distinto nivel de protección para cada uno de ellos:

Solo se autorizará la investigación en la que se utilicen preembriones in vitro viables si es de carácter diagnóstico o con finalidad terapéutica o preventiva y siempre que no se modifique el patrimonio genético no patológico.

La investigación con preembriones in vitro no viables solo podrá realizarse, fuera de la comprobación de su viabilidad o con carácter diagnóstico, previa demostración de la inviabilidad del modelo animal de investigación.

La investigación o experimentación sobre los gametos o con ellos, no supone atentado alguno del derecho a la vida... porque solo resultan permitidas en la medida en que tengan por objeto embriones no viables.

Un eventual resultado de hibridación viene impedido por la Ley, que tipifica como infracción muy grave el intercambio genético humano o recombinado con otras especies para producción de híbridos.

Respecto a la patrimonialización, admite que sería contraria a la dignidad humana, pero que no se da el caso por tratarse de fetos, embriones muertos o no viables, y porque se excluye expresamente cualquier causa lucrativa o remuneratoria.

El principal problema que se plantea es nuevamente el de la determinación de la condición humana, titular de la dignidad, de los fetos y embriones. Pedro Serna, en el citado artículo, formula la siguiente crítica: 
" todo ser humano actualmente viviente es merecedor de respeto en virtud de su dignidad, pero para llegar a su actual status ha debido ser antes necesariamente embrión y feto, sostener que un instante, el del nacimiento, las 24 horas de vida independiente, son los hechos que nos convierten en seres dignos, merecedores de respeto, no deja de ser un atentado contra esa dignidad".

El debate sobre el derecho de los embriones se planteó jurídicamente en el famoso caso de Mary Sue Davis (1989), cuando reivindicó el derecho de que le fueran transferidos, para garantizar su derecho a nacer, frente a la negativa de la paternidad de su ex -marido. En primera instancia el juez reconoció el carácter de individuos humanos de los embriones y su titularidad de derechos, el Tribunal Supremo revocó la sentencia concediendo prioridad a la pretensión de no paternidad. (15)

Desde las perspectivas ético-liberales, se admitiría el nacimiento por clonación a partir de la transferencia de núcleo en un óvulo, que puede realizarse a partir de una célula somática de hombre o de mujer, con la posibilidad de que la mujer use su óvulo para clonar con una célula somática propia. Se niega que durante los primeros meses de gestación existan cualidades psicológicas que impongan exigencias morales específicas que permitan asentar la presencia de una persona moral. Igualmente, consideran inaceptable la defensa de un orden natural con una racionalidad inherente que orienta todos los procesos de conservación. Las intervenciones científicas tendrían como límite ese orden natural.(16)

¿Cómo construir el consenso de contenido mínimo?. Parece que se abre un espacio de consenso relativo al establecimiento de límites a la investigación biotécnica. La reivindicación de una absoluta libertad científica amparada en la mejora del conocimiento y del progreso humano es en nuestros días de carácter minoritario.

La comunidad científica está hoy más sensibilizada sobre estos límites, y se acepta la reflexión ética como pauta de orientación de la praxis científica, especialmente en la investigación con material biológico humano. 
También parece haber coincidencia, dentro de esta necesidad de limitación, en ciertos principios éticos como el del libre consentimiento, la prevalencia del interés del individuo sobre los intereses de la ciencia y de la sociedad, el principio de beneficencia, el sometimiento a conocimiento y control de los programas de investigación que se propongan, la defensa de la biodiversidad, el respeto a la dignidad de la persona, la finalidad terapéutica, etc. (17)

Nunca como en la actualidad se ha producido una preocupación por la aproximación de ciencia y ética a través de la búsqueda de un consenso colectivo. Nunca como en la actualidad el consenso se conforma como un ideal que permita orientar todo tipo de práctica social, científica o política. El diálogo debe ser el principal fundamento de la convivencia pacífica en un universo multicultural. Solo a través del diálogo será posible establecer unos contenidos éticos que puedan ser asumidos de modo universal y transformados en fundamento moral de los ordenamientos jurídicos. (18) 
1 Casese, A.; "Los derechos humanos en el mundo contemporáneo", Ariel, Barcelona, 1991.

2 Cortina, A.; "Ética Mínima: Introducción a la filosofía política", Tecnos, Madrid, 1986. Vid. también, Gracia, D.;'Fundamentos de bioética", Eudema, Madrid, 1989.

4 Kant, I.; "Metafísica de las costumbres", UNAM, México, 1968.

5 Adorno, T. W.; "La disputa del positivismo", Grijalbo, Barcelona, 1967.

6 Roberto Andorno: Bioética y dignidad de la persona, 1998, Madrid, Tecnos, pag.42.

7 Perez-Luño, A.E.;"Derechos Humanos, Estado de Derecho y Constitución", Tecnos, Madrid, 1984.

8 Alvarez Conde, E.; "Curso de Derecho Constitucional", Tecnos, Madrid, 1999. (Esta cuestión ha sido tratada por autores como $\mathrm{J}$. Arozamena, J. Leguina, X. Pibernat

9 Serna, P.; "Dignidad de la persona: un estudio jurisprudencial", Persona y Derecho, n 41, 1999.

10 Lucas Verdú, P.; "Curso de Derecho Político", Tecnos, Madrid, 1984.

11 Martín Mateo, R.; "Bioética y Derecho" (1987), Ariel, Barcelona, 1987.
12 Atienza, M.; "Juridificar la Bioética", en R. Vazquez (compilador), FCE, México, 1999.

13 Palacios, M ; "Bioética práctica para el SXXI", Oviedo, Ediciones Nobel, 2000.

14 Singer, P.; "Should the Baby Live?", Oxford University Press, 1985.

15 Bruaire, C.: "Une éthique pour la médecine", Fayard, París, 1978. Vid. también, Vazquez, R.;"Una justificación liberal de la clonación", en "Perspectivas bioéticas", año 4, Bs. As. 1999.

16 Vid. Lejeune, J.; "Qué es el embrión humano?", Rialp, Madrid, 1993.

17 Vazquez, R.; "Una justificación liberal de la clonación", en "Bioética y derecho", 1999. Vid. Dworkin, R.; "El dominio de la vida", Ariel, Barcelona,1994.

18 Vid. Consejo Interterritorial del Sistema Nacional de Salud; "Documento del consenso", Revista española de trasplantes, vol. 2. Vid. también, Pompidou, A.; "Bioética: un compromiso compartido", op. cit. Pág. 37-48. Vid. "Convenio sobre la biodiversidad biológica", Rio de Janeiro, 1992.

19 Romeo Casabona, C. M". ; "La biotecnología y los principios de eficacia, seguridad y precaución, Oviedo, 2000. 
VID. LORCA NAVARRETE, J.F.; "Derechos fundamentales y jurisprudencia", Pirámide, Madrid, 2001.

AUTO TC 266/1982; Recurso de amparo en delitos de aborto.

STC 53/1985 (BOE de 18-05-85); Recurso previo de inconstitucionalidad de Proyecto de Ley Orgánica de Reforma del art. 417 bis, del Código Penal, despenalizando el aborto en determinados supuestos.

AUTO TC 13/ 1989; inadmisión de Recurso de amparo relativo a la aplicación del RD 2409/1986, sobre centros acreditados y dictámenes preceptivos en interrupción del embarazo.

STC 37/1989 (BOE de 2-03-89); Recurso de amparo respecto a "intimidad corporal" $y$ reconocimiento médico en investigación penal (posible delito de aborto).
STC 120/1990 (BOF, de 27-07-90); Recurso de amparo relativo a prestación de asistencia médica a recluso en huelga de hambre.

STC 215/1994 (BOE de 18-08-94); Cuestión de inconstitucionalidad relativa a esterilización de incapaz.

STC 166/1996 (BOF, de....), trasfusiones de sangre a Testigo de Jehová.

STC 212/1996 (BOE de 22-01-97); Recurso de inconstitucionalidad respecto a la Ley 42/1988 de donación y utilización de embriones...

Auto TC 261/1998; Cuestión de inconstitucionalidad relativa a esterilización de deficiente psíquico.

STC 116/1999 (BOE de 8-07-99); Recurso de inconstitucionalidad respecto a la Ley 35/ 1988. 